\title{
APPROXIMATING FIXED POINTS OF NONSELF CONTRACTIVE TYPE MAPPINGS IN BANACH SPACES ENDOWED WITH A GRAPH
}

\author{
Laszlo Balog, Vasile Berinde and Mădălina Păcurar
}

Dedicated to Professor Ravi P. Agarwal

\begin{abstract}
Let $K$ be a non-empty closed subset of a Banach space $X$ endowed with a graph $G$. We obtain fixed point theorems for nonself $G$-contractions of Chatterjea type. Our new results complement and extend recent related results [Berinde, V., Păcurar, M., The contraction principle for nonself mappings on Banach spaces endowed with a graph, J. Nonlinear Convex Anal. 16 (2015), no. 9, 1925-1936; Balog, L., Berinde, V., Fixed point theorems for nonself Kannan type contractions in Banach spaces endowed with a graph, Carpathian J. Math. 32 (2016), no. 3 (in press)] and thus provide more general and flexible tools for studying nonlinear functional equations.
\end{abstract}

\section{Introduction}

Let $X, Y$ be linear spaces and $F: D \subset X \rightarrow Y$ be a nonlinear mapping. One of the most effective ways to solve the equation

$$
F(x)=0, x \in D
$$

Key Words: Banach space; Graph; Fixed point; Property (M); Error estimate.

2010 Mathematics Subject Classification: Primary 47H10, 47H09; Secondary 47J05, $47 \mathrm{~J} 25$.

Received: 15.01.2016.

Accepted: 23.04.2016. 
is to convert it equivalently into a fixed point problem of the form

$$
x=T(x), x \in K,
$$

where $T: K \subset X \rightarrow X$ is a mapping constructed by a certain scheme.

For example, in the case of the well-known Newton method, considered here for the sake of simplicity in $X=\mathbb{R}$, the iteration function $F$ involved in $(1.2)$ is given by:

$$
T x=x-F(x) / F^{\prime}(x), x \in K .
$$

The equivalent form (1.2) of equation (1.1) is extremely important for at least two major reasons:

1. Problem (1.2) can be solved by applying a suitable fixed point theorem, thus obtaining an existence or an existence and uniqueness result for the original problem (1.1);

2. The particular form of problem (1.2) now provides a direct way to construct a simple iterative scheme to approximate the solution (s) of (1.1), i.e.,

$$
x_{n+1}=T x_{n}, n \geq 0,
$$

with $x_{0} \in K$ the starting value.

One of the most important and flexible tools in nonlinear analysis to deal with a problem of the form (1.2) is the well-known Banach contraction principle, stated here in its complete form, see for example [19].

Theorem 1. Let $(X, d)$ be a complete metric space and $T: X \rightarrow X$ a strict contraction, i.e., a map satisfying

$$
d(T x, T y) \leq a d(x, y), \quad \text { for all } x, y \in X,
$$

where $0 \leq a<1$ is constant. Then:

(p1) $T$ has a unique fixed point $p$ in $X$ (i.e., Tp=p);

$(p 2)$ The Picard iteration $\left\{x_{n}\right\}_{n=0}^{\infty}$ defined by

$$
x_{n+1}=T x_{n}, \quad n=0,1,2, \ldots
$$

converges to $p$, for any $x_{0} \in X$.

(p3) The following estimate holds

$$
d\left(x_{n+i-1}, p\right) \leq \frac{a^{i}}{1-a} d\left(x_{n}, x_{n-1}\right), \quad n=0,1,2, \ldots ; i=1,2, \ldots
$$


As it can be seen from (1.3), Theorem 1 can be applied only to nonlinear equations (1.2) with $T$ a continuous self mapping.

But, most of the concrete problems of the form (1.1) or (1.2) we may encounter in pure and applied mathematics involve generallydiscontinuous and/or non-self mappings $T$. This demand motivated authors to search for more general and more flexible fixed point tools that could be applied to such general nonlinear problems.

Kannan [42] has been the first one to consider in this context discontinuous self mappings $T$, by considering instead of (1.3) the following alternative and

independent contractive condition: there exists a constant $a \in\left[0, \frac{1}{2}\right)$ such that

$$
d(T x, T y) \leq a[d(x, T x)+d(y, T y)], \quad \text { for all } x, y \in X .
$$

On the other hand, the study of non-self mappings started with the paper by Caristi [28], in the case of nonself single-valued contractions, and with the paper by Assad and Kirk [13], for non-self multi-valued contractive mappings $T: K \rightarrow \mathcal{P}(X)$, where $(X, d)$ is a convex metric space in the sense of Menger and $K$ is a non-empty closed subset of $X$.

For some recent and more general results on this topic we refer to [16], [17], [19], [3], [4] and references therein. In a recent paper [20], the second author and M. Păcurar established two fixed point theorems for non self contractions defined on Banach spaces endowed with a graph, while very recently [15], the present authors extended these results to non-self Kannan type contractions $T: X \rightarrow X$ on Banach spaces endowed with a graph.

The main aim of the present work is to extend the results in [20] and [15] to the case of mappings satisfying a dual condition of (1.6) which is due to Chatterjea [30] and is independent of both contractive condition (1.3) and (1.6): there exists $a \in\left(0, \frac{1}{2}\right)$ such that

$$
d(T x, T y) \leq a[d(x, T y)+d(y, T x)], \quad \text { for all } x, y \in X .
$$

To accomplish this task, we need some basic prerequisites related to fixed point theorems for self and non self contractions in Banach spaces or convex metric spaces endowed with a graph, basically taken from [20] and [15], and which are presented in the next section.

\section{Metric spaces endowed with a graph}

Let $(X, d)$ be a metric space and let $\Delta$ denote the diagonal of the Cartesian product $X \times X$. Consider now a directed simple graph $G=(V(G), E(G))$ 
such that the set of its vertices, $V(G)$, coincides with $X$ and $E(G)$, the set of its edges, contains all loops, i.e., $\Delta \subset E(G)$.

By $G^{-1}$ we denote the converse graph of $G$, i.e., the graph obtained by $G$ by reversing its edges, i.e.,

$$
E\left(G^{-1}\right)=\{(y, x) \in X \times X:(x, y) \in E(G)\} .
$$

If $x, y$ are vertices in the graph $G$, then a path from $x$ to $y$ of length $N$ is a sequence $\left\{x_{i}\right\}_{i=1}^{N}$ of $N+1$ vertices of $G$ such that

$$
x_{0}=x, x_{N}=y \text { and }\left(x_{i-1}, x_{i}\right) \in E(G), i=1,2, \ldots, N .
$$

A graph $G$ is said to be connected if there is at least a path between any two vertices. If $G=(V(G), E(G))$ is a graph and $H \subset V(G)$, then the graph $(H, E(H))$ with $E(H)=E(G) \cap(H \times H)$ is called the subgraph of $G$ determined by $H$. Denote it by $G_{H}$.

If $\tilde{G}=(X, E(\tilde{G}))$ is the symmetric graph obtained by putting together the vertices of both $G$ and $G^{-1}$, i.e.,

$$
E(\tilde{G})=E(G) \cup E\left(G^{-1}\right),
$$

then $G$ is called weakly connected if $\tilde{G}$ is connected.

A mapping $T: X \rightarrow X$ is said to be (well) defined on a metric space endowed with a graph $G$ if it has the property

$$
\forall x, y \in X,(x, y) \in E(G) \text { implies }(T x, T y) \in E(G) .
$$

According to [41], a mapping $T: X \rightarrow X$, which is well defined on a metric space endowed with a graph $G$, is called a $G$-contraction if there exists a constant $\alpha \in(0,1)$ such that for all $x, y \in X$ with $(x, y) \in E(G)$ we have

$$
d(T x, T y) \leq \alpha \cdot d(x, y) .
$$

Example 1. If $G_{0}$ is the complete graph on $X$, that is, $E\left(G_{0}\right)=X \times X$, then a $G_{0}$-contraction is a usual contraction in the sense of Banach, i.e., it satisfies condition (1.3), while a $G_{0}$-Kannan contraction is a usual Kannan contraction, i.e., it satisfies condition (1.6).

\section{Main results}

Let $X$ be a Banach space, $K$ a nonempty closed subset of $X$ and $T: K \rightarrow X$ a non-self mapping. If $x \in K$ is such that $T x \notin K$, then we can always choose 
an $y \in \partial K$ (the boundary of $K)$ such that $y=(1-\lambda) x+\lambda T x(0<\lambda<1)$, which actually expresses the fact that

$$
d(x, T x)=d(x, y)+d(y, T x), y \in \partial K,
$$

where we denoted $d(x, y)=\|x-y\|$.

In general, the set $Y$ of points $y$ satisfying condition (3.1) above may contain more than one element. We suppose $Y$ is always nonempty.

In this context we shall need the following important concept first introduced and used in [19].

Definition 1. Let $X$ be a Banach space, $K$ a nonempty closed subset of $X$ and $T: K \rightarrow X$ a non-self mapping. Let $x \in K$ with $T x \notin K$ and let $y \in \partial K$ be the corresponding elements given by (3.1). If, for any such elements $x$, we have

$$
d(y, T y) \leq d(x, T x),
$$

for all corresponding $y \in Y$, then we say that $T$ has property $(M)$.

Note that the non-self mapping $T$ in the next example has property $(M)$.

Example 2. ([20], Example 4) Let $X=[0,1] \cup\{3\}$ be endowed with the usual norm and let $K=\{0,1,3\}$. Consider the function $T: K \rightarrow X$, defined by $T x=0$, for $x \in\{0,1\}$ and $T 3=0.5$. As the only value $x \in K$ with $T x \notin K$ is $x=3$ and to it corresponds the set $Y=\{1\}$, and since

$$
d(y, T y)=d(1, T 1)=|1-0|<|3-0.5|=d(3, T 3)=d(x T x),
$$

property $(M)$ obviously holds.

A condition quite similar to (3.2), called inward condition, has been used by Caristi [28] to obtain a generalization of contraction mapping principle for non self mappings. The inward condition is more general than property $(\mathrm{M})$ since it does not require $y$ in (3.1) to belong to $\partial K$, see also [37] (this has been communicated to us by Professor Rus [69]).

Note also that, in general, the set $Y$ of points $y$ satisfying condition (3.1) above may contain more than one element.

For a non self mapping $T: K \rightarrow X$ we shall say that it is (well) defined on the Banach space $X$ endowed with the graph $G$ if it has this property for the subgraph of $G$ induced by $K$, that is,

$$
(x, y) \in E(G) \text { with } T x, T y \in K \text { implies }(T x, T y) \in E(G) \cap(K \times K),
$$

for all $x, y \in K$.

The next theorem establishes a fixed point theorem for non self Chatterjea contractions defined on a Banach space endowed with a graph. 
Theorem 2. Let $(X, d, G)$ be a Banach space endowed with a simple directed and weakly connected graph $G$ such that the property $(L)$ holds, i.e., for any sequence $\left\{x_{n}\right\}_{n=1}^{\infty} \subset X$ with $x_{n} \rightarrow x$ as $n \rightarrow \infty$ and $\left(x_{n}, x_{n+1}\right) \in E(G)$ for all $n \in \mathbb{N}$, there exists a subsequence $\left\{x_{k_{n}}\right\}_{n=1}^{\infty}$ satisfying

$$
\left(x_{k_{n}}, x\right) \in E(G), \forall n \in \mathbb{N} .
$$

Let $K$ be a nonempty closed subset of $X$ andlet $T: K \rightarrow X$ be a Chatterjea contraction, i.e., a mapping for which there exists a constant $a \in[0,1 / 2)$ such that

$$
d(T x, T y) \leq a[d(x, T y)+d(y, T x)], \text { for all }(x, y) \in E\left(G_{K}\right),
$$

where $G_{K}$ is the subgraph of $G$ determined by $K$.

If $K_{T}:=\{x \in \partial K:(x, T x) \in E(G)\} \neq \emptyset, T$ has property (M) satisfies Rothe's boundary condition

$$
T(\partial K) \subset K,
$$

then

(i) $\operatorname{Fix}(T)=\left\{x^{*}\right\}$;

(ii) Picard iteration $\left\{x_{n}=T^{n} x_{0}\right\}_{n=1}^{\infty}$ converges to $x^{*}$, for all $x_{0} \in K_{T}$, and the following estimate holds

$$
d\left(x_{n}, x^{*}\right) \leq \frac{\delta^{[n / 2]}}{1-\delta} \max \left\{d\left(x_{0}, x_{1}\right), d\left(x_{1}, x_{2}\right)\right\}, \quad n=0,1,2, \ldots
$$

where $\delta=\frac{a}{1-a}$.

Proof. If $T(K) \subset K$, then $T$ is actually a self mapping of the closed set $K$ and the conclusion follows by Chatterjea fixed point theorem [30] with $X=K$. Therefore, in the following we consider only the case $T(K) \not \subset K$. Let $x_{0} \in K_{T}$. This means that $\left(x_{0}, T x_{0}\right) \in E(G)$ and in view of (2.1), we have

$$
\left(T^{n} x_{0}, T^{n+1} x_{0}\right) \in E(G), \forall n \in \mathbb{N} .
$$

Denote $y_{n}:=T^{n} x_{0}$, for all $n \in \mathbb{N}$.

By (3.6) it also follows that $T x_{0} \in K$.

Denote $x_{1}:=y_{1}=T x_{0}$. Now, if $T x_{1} \in K$, set $x_{2}:=y_{2}=T x_{1}$. If $T x_{1} \notin K$, we can choose an element $x_{2}$ on the segment $\left[x_{1}, T x_{1}\right]$ which also belong to $\partial K$, that is,

$$
x_{2}=(1-\lambda) x_{1}+\lambda T x_{1}(0<\lambda<1) .
$$

Continuing in this way we obtain two sequences $\left\{x_{n}\right\}$ and $\left\{y_{n}\right\}$ whose terms satisfy one of the following properties: 
i) $x_{n}:=y_{n}=T x_{n-1}$, if $T x_{n-1} \in K$;

ii) $x_{n}=(1-\lambda) x_{n-1}+\lambda T x_{n-1} \in \partial K(0<\lambda<1)$, if $T x_{n-1} \notin K$.

To simplify the argumentation in the proof, let us denote

$$
P=\left\{x_{k} \in\left\{x_{n}\right\}: x_{k}=y_{k}=T x_{k-1}\right\}
$$

and

$$
Q=\left\{x_{k} \in\left\{x_{n}\right\}: x_{k} \neq T x_{k-1}\right\} .
$$

Note that $\left\{x_{n}\right\} \subset K$ for all $n \in \mathbb{N}$ and that, if $x_{k} \in Q$, then both $x_{k-1}$ and $x_{k+1}$ belong to the set $P$.

Moreover, by virtue of (3.6), we cannot have two consecutive terms of $\left\{x_{n}\right\}$ in the set $Q$ (but we can have two consecutive terms of $\left\{x_{n}\right\}$ in the set $P)$.

We claim that $\left\{x_{n}\right\}$ is a Cauchy sequence.

To prove this, we must discuss three different cases: Case I. $x_{n}, x_{n+1} \in P$; Case II. $x_{n} \in P, x_{n+1} \in Q$; Case III. $x_{n} \in Q, x_{n+1} \in P$;

Case I. $x_{n}, x_{n+1} \in P$.

In this case we have $x_{n}=y_{n}=T x_{n-1}, x_{n+1}=y_{n+1}=T x_{n}$, and hence

$$
d\left(x_{n+1}, x_{n}\right)=d\left(y_{n+1}, y_{n}\right)=d\left(T x_{n}, T x_{n-1}\right) .
$$

Since $\left\{x_{n}\right\} \subset K$ for all $n \in \mathbb{N}$, by $(3.8)\left(x_{n}, x_{n-1}\right) \in E\left(G_{K}\right)$, and so by the contraction condition (3.5), we get

$$
\begin{gathered}
d\left(x_{n+1}, x_{n}\right)=d\left(T x_{n}, T x_{n-1}\right) \leq a\left[d\left(x_{n}, T x_{n-1}\right)+d\left(x_{n-1}, T x_{n}\right)\right] \\
=a d\left(x_{n-1}, x_{n+1}\right) \leq a\left[d\left(x_{n-1}, x_{n}\right)+d\left(x_{n}, x_{n+1}\right)\right]
\end{gathered}
$$

by triangle inequality, and this leads to

$$
d\left(x_{n+1}, x_{n}\right) \leq \delta d\left(x_{n}, x_{n-1}\right),
$$

where $\delta=\frac{a}{1-a}$.

Case II. $x_{n} \in P, x_{n+1} \in Q$.

In this case we have $x_{n}=y_{n}=T x_{n-1}$, but $x_{n+1} \neq y_{n+1}=T x_{n}$ and

$$
d\left(x_{n}, x_{n+1}\right)+d\left(x_{n+1}, T x_{n}\right)=d\left(x_{n}, T x_{n}\right) .
$$

Thus $d\left(x_{n+1}, T x_{n}\right) \neq 0$ and hence

$$
d\left(x_{n}, x_{n+1}\right)=d\left(x_{n}, T x_{n}\right)-d\left(x_{n+1}, T x_{n}\right)<d\left(x_{n}, T x_{n}\right) .
$$


Now, by a similar argument to that in Case I, $\left(x_{n}, x_{n-1}\right) \in E\left(G_{K}\right)$ and hence by the contraction condition (3.5) we get

$$
\begin{gathered}
d\left(x_{n}, T x_{n}\right)=d\left(T x_{n-1}, T x_{n}\right) \leq a\left[d\left(x_{n-1}, T x_{n}\right)+d\left(x_{n}, T x_{n-1}\right)\right] \\
=a d\left(x_{n-1}, T x_{n}\right) \leq a\left[d\left(x_{n-1}, x_{n}\right)+d\left(x_{n}, T x_{n}\right)\right] .
\end{gathered}
$$

Thus

$$
d\left(x_{n}, T x_{n}\right) \leq \delta d\left(x_{n}, x_{n-1}\right) .
$$

and therefore, by means of 3.10 ,

$$
d\left(x_{n}, x_{n+1}\right)<d\left(x_{n}, T x_{n}\right) \leq \delta d\left(x_{n}, x_{n-1}\right) .
$$

which is exactly inequality (3.9) obtained in Case I.

Case III. $x_{n} \in Q, x_{n+1} \in P$. In this case we have $x_{n+1}=T x_{n}, x_{n} \neq$ $y_{n}=T x_{n-1}$ and

$$
d\left(x_{n-1}, x_{n}\right)+d\left(x_{n}, T x_{n-1}\right)=d\left(x_{n-1}, T x_{n-1}\right) .
$$

Hence, by property (M) we get

$$
d\left(x_{n}, x_{n+1}\right)=d\left(x_{n}, T x_{n}\right) \leq d\left(x_{n-1}, T x_{n-1}\right)=d\left(T x_{n-2}, T x_{n-1}\right) .
$$

(since $x_{n} \in Q \Longrightarrow x_{n-1} \in P$ ). Thus,

$$
d\left(x_{n}, x_{n+1}\right) \leq d\left(T x_{n-2}, T x_{n-1}\right) .
$$

Since, by (3.8), $\left(y_{n-1}, y_{n}\right) \in E(G)$, by the contraction condition (3.5) with $x:=x_{n-2}$ and $y:=x_{n-1}$ we obtain

$$
\begin{aligned}
d\left(T x_{n-2}, T x_{n-1}\right) \leq & a\left[d\left(x_{n-2}, T x_{n-1}\right)+d\left(x_{n-1}, T x_{n-2}\right)\right] \\
& =a d\left(x_{n-2}, x_{n}\right),
\end{aligned}
$$

since $x_{n-1}=T x_{n-2}$. Therefore, by triangle inequality,

$$
\begin{gathered}
d\left(x_{n}, x_{n+1}\right) \leq a d\left(x_{n-2}, x_{n}\right) \leq a\left[d\left(x_{n-2}, x_{n-1}\right)+d\left(x_{n-1}, x_{n}\right)\right] \\
=2 a \cdot \frac{d\left(x_{n-2}, x_{n-1}\right)+d\left(x_{n-1}, x_{n}\right)}{2} \leq 2 a \max \left\{d\left(x_{n-2}, x_{n-1}\right), d\left(x_{n-1}, x_{n}\right)\right\} .
\end{gathered}
$$

Since $\max \left\{2 a, \frac{a}{1-a}\right\}=\frac{a}{1-a}:=\delta$, we finally obtain

$$
d\left(x_{n}, x_{n+1}\right) \leq \delta d\left(x_{n-2}, x_{n-1}\right) .
$$


Now, by summaryzing all three cases and using (3.9) and (3.12), it follows that the sequence $\left\{d\left(x_{n}, x_{n-1}\right)\right\}$ satisfies the inequality

$$
d\left(x_{n}, x_{n+1}\right) \leq \delta \max \left\{d\left(x_{n-2}, x_{n-1}\right), d\left(x_{n-1}, x_{n}\right)\right\},
$$

for all $n \geq 2$. Now, by induction for $n \geq 2$, from (3.13) one obtains

$$
d\left(x_{n}, x_{n+1}\right) \leq \delta^{[n / 2]} \max \left\{d\left(x_{0}, x_{1}\right), d\left(x_{1}, x_{2}\right)\right\},
$$

where $[n / 2]$ denotes the greatest integer not exceeding $n / 2$.

Further, for $m>n>N$,

$$
d\left(x_{n}, x_{m}\right) \leq \sum_{i=N}^{\infty} d\left(x_{i}, x_{i-1}\right) \leq 2 \frac{\delta^{[N / 2]}}{1-\delta} \max \left\{d\left(x_{0}, x_{1}\right), d\left(x_{1}, x_{2}\right)\right\},
$$

which shows that $\left\{x_{n}\right\}$ is a Cauchy sequence.

Since $\left\{x_{n}\right\} \subset K$ and $K$ is closed, $\left\{x_{n}\right\}$ converges to some point $x^{*}$ in $K$, i.e.,

$$
x^{*}=\lim _{n \rightarrow \infty} x_{n} .
$$

By property $(L)$, there exists a subsequence $\left\{x_{k_{n}}\right\}_{n=1}^{\infty}$ of $\left\{x_{n}\right\}_{n=1}^{\infty}$ satisfying

$$
\left(x_{k_{n}}, x^{*}\right) \in E(G), \forall n \in \mathbb{N} \text {. }
$$

and hence, by the contraction condition (3.5),

$$
\begin{gathered}
d\left(x_{k_{n}+1}, T x^{*}\right)=d\left(T x_{k_{n}}, T x^{*}\right) \leq a\left[d\left(x_{k_{n}}, T x^{*}\right)+d\left(x^{*}, T x_{k_{n}}\right]\right. \\
\leq a\left[d\left(x_{k_{n}}, T x_{k_{n}}\right)+d\left(T x_{k_{n}}, T x^{*}\right)+d\left(x^{*}, x_{k_{n}+1}\right] .\right. \\
=a\left[d\left(x_{k_{n}}, T x_{k_{n}}\right)+d\left(x_{k_{n}+1}, T x^{*}\right)+d\left(x^{*}, x_{k_{n}+1}\right] .\right.
\end{gathered}
$$

This yields,

$$
d\left(x_{k_{n}+1}, T x^{*}\right) \leq \delta d\left(x_{k_{n}}, T x_{k_{n}}\right)+a d\left(x^{*}, x_{k_{n}+1}\right],
$$

which, by means of (3.15) and by letting $n \rightarrow \infty$ shows that the sequence $\left\{x_{k_{n}}\right\}_{n=1}^{\infty}$ converges to $T x^{*}$ as $n \rightarrow \infty$. By (3.16) and the uniqueness of the limit in a metric space, we infer that $x^{*}=T x^{*}$, i.e., $x^{*}$ is a fixed point of $T$.

The uniqueness of $x^{*}$ immediately follows by the contraction condition (3.5), which implies the uniqueness condition

$$
d(T x, T y) \leq \delta d(x, y)+2 \delta d(x, T x) \text {, for all }(x, y) \in E\left(G_{K}\right) .
$$

In the end, by using the estimate (3.14) and triangle inequality we obtain for any $n, p \in \mathbb{N}^{*}$

$$
d\left(x_{n}, x_{n+p}\right) \leq \delta^{[n / 2]} \frac{1-\delta^{[(p+1) / 2]}}{1-\delta} \max \left\{d\left(x_{0}, x_{1}\right), d\left(x_{1}, x_{2}\right)\right\},
$$

from which, by letting $p \rightarrow \infty$, we get exactly the error estimate (3.7). 
A weaker form of Theorem 2 can be stated as follows.

Theorem 3. Let $(X, d, G)$ be a Banach space endowed with a simple directed and weakly connected graph $G$. Let $K$ be a nonempty closed subset of $X$ and $T: K \rightarrow X$ be a $G$-Chatterjea contraction on $K$.

If $K_{T}:=\{x \in \partial K:(x, T x) \in E(G)\} \neq \emptyset, T$ is orbitally $G$-continuous and $T$ satisfies Rothe's boundary condition

$$
T(\partial K) \subset K
$$

then the conclusion of Theorem 2 remains valid.

\section{Conclusions and further study}

The Chatterjea-type contractive condition (1.7) (or (3.5) in the non self mapping case) is independent of the Banach type contraction condition (1.3) considered in [20], and of Kannan-type contractive condition (1.6), as shown by the next examples.

Example 3. ([53], Example 1.3.1) Let $X=[0,1]$ with the usual norm and $T:[0,1] \rightarrow[0,1]$ be defined by

$$
T(x)= \begin{cases}\frac{2}{5}, & x \in\left[0, \frac{2}{3}\right) \\ \frac{1}{5}, & x \in\left[\frac{2}{3}, 1\right] .\end{cases}
$$

Then $T$ is a discontinuous Kannan operator with constant $a=\frac{3}{7}$, it is neither a Banach contraction nor a Chatterjea contraction.

Example 4. ([53], Example 1.3.4) Let $X=[0,1]$ with the usual norm and $f:[0,1] \rightarrow[0,1]$ be defined by

$$
f(x)= \begin{cases}\frac{1}{5}, & x \in\left[0, \frac{8}{15}\right) \\ \frac{1}{3}, & x \in\left[\frac{8}{15}, 1\right] .\end{cases}
$$

Then $f$ is a Chatterjea operator with constant $a=\frac{2}{5}$ but $f$ is neither a Banach contraction nor a Kannan contraction (see Example 1.3.7 in [53] for the proof). 
This shows that Theorems 2 and 3 established in the present paper are important and very general alternative fixed point theorems for non self mappings in Banach spaces endowed with a graph. They provide effective generalisations and extensions of similar results in literature and subsume several important results in the fixed point theory of self and nonself mappings.

Both Theorem 2 and Theorem 3 were established in Banach spaces endowed with a graph for the sake of simplicity of exposition but they can be transposed in more general settings, like convex metric spaces or $C A T(0)$ spaces without any major technical difficulty.

By working on Banach spaces endowed with a graph, our results are valid not only for mappings that satisfy the contraction condition (3.5) for all pairs $(x, y)$ of the space $X \times X$, but only for the pairs $(x, y)$ which are vertices of a simple directed and weakly connected graph $G=(X, E(G))$, with $E(G) \subset X \times X$.

Amongst the most important particular cases of Theorem 2 and Theorem 3 , we mention in the following just the following ones:

1. If $G$ is the graph $G_{0}$ in Example 1, then by Theorem 2 we obtain an extension of Chatterjea fixed point theorem [30] for non self mappings, restricted here for the reasons mentioned above to Banach spaces instead of usual complete metric spaces.

2. If $K=X$, and $G$ is the graph $G_{0}$ in Example 1, then by Theorem 2 we obtain the original Chatterjea fixed point theorem [30] for self mappings, restricted here for the reasons mentioned above to Banach spaces instead of usual complete metric spaces.

For further developments, we have in view considering nonself singlevalued as well as multi-valued mappings by starting from the corresponding case of self mappings, see [1]-[4],[5], [21], [22], [25], [32], [33], [38], [39], [40], [43], [44], [50]-[59], [71]-[73], [74]-[77] etc.

\section{Acknowledgements}

The second author's research was done during his visit to Department of Mathematics and Statistics, King Fahd University of Petroleum and Minerals, Dhahran, Saudi Arabia, in the period April-May 2016. He gratefully thanks Dr. Al-Homidan, dean of College of Sciences, and Dr. Al-Attas, the Chairman of the Department of Mathematics and Statistics, for the excellent conditions they offered during the visit. The second author would also like to acknowledge the support provided by the Deanship of Scientific Research at King Fahd University of Petroleum and Minerals for funding this work through the projects IN151014 and IN151017. 


\section{References}

[1] Abbas, M., Ali, B., Petruşel, G., Fixed points of set-valued contractions in partial metric spaces endowed with a graph. Carpathian J. Math. 30 (2014), no. 2, 129-137.

[2] Agarwal, R.P., El-Gebeily, M.A. and O'Regan, D., Generalized contractions in partially ordered metric spaces, Appl. Anal. 87 (2008) 1-8

[3] Alghamdi, Maryam A., Berinde, V. and Shahzad, N., Fixed points of multi-valued non-self almost contractions, J. Appl. Math. Volume 2013, Article ID 621614, 6 pages

[4] Alghamdi, Maryam A., Berinde, V. and Shahzad, N., Fixed points of non-self almost contractions, Carpathian J. Math. 33 (2014), No. 1, 1-8

[5] Ariza-Ruiz, D., Jiménez-Melado, A., A continuation method for weakly Kannan maps. Fixed Point Theory Appl. 2010, Art. ID 321594, 12 pp.

[6] Assad, N. A. On a fixed point theorem of Iséki, Tamkang J. Math. 7 (1976), no. 1, 19-22

[7] Assad, N. A. On a fixed point theorem of Kannan in Banach spaces, Tamkang J. Math. 7 (1976), no. 1, 91-94

[8] Assad, N. A., On some nonself nonlinear contractions, Math. Japon. 33 (1988), no. $1,17-26$

[9] Assad, N. A., On some nonself mappings in Banach spaces, Math. Japon. 33 (1988), no. 4, 501-515

[10] Assad, N. A., Approximation for fixed points of multivalued contractive mappings, Math. Nachr. 139 (1988), 207-213

[11] Assad, N. A., A fixed point theorem in Banach space, Publ. Inst. Math. (Beograd) (N.S.) 47(61) (1990), 137-140

[12] Assad, N. A., A fixed point theorem for some non-self-mappings, Tamkang J. Math. 21 (1990), no. 4, 387-393

[13] Assad, N. A. and Kirk, W. A., Fixed point theorems for set-valued mappings of contractive type, Pacific J. Math. 43 (1972), 553-562

[14] Assad, N. A. Sessa, S., Common fixed points for nonself compatible maps on compacta, Southeast Asian Bull. Math. 16 (1992), No.2, 91-95 
[15] Balog, L., Berinde, V., Fixed point theorems for nonself Kannan type contractions in Banach spaces endowed with a graph, Carpathian J. Math. 32 (2016), no. 3 (in press).

[16] Berinde, V., A common fixed point theorem for nonself mappings. Miskolc Math. Notes 5 (2004), no. 2, 137-144

[17] Berinde, V., Approximation of fixed points of some nonself generalized $\phi$-contractions. Math. Balkanica (N.S.) 18 (2004), no. 1-2, 85-93

[18] Berinde, V., Iterative Approximation of Fixed Points, 2nd Ed., Springer Verlag, Berlin Heidelberg New York, 2007

[19] Berinde, V., Păcurar, Mădălina, Fixed point theorems for nonself singlevalued almost contractions, Fixed Point Theory, 14 (2013), No. 2, 301-312

[20] Berinde, V., Păcurar, Mădălina, The contraction principle for nonself mappings on Banach spaces endowed with a graph, J. Nonlinear Convex Anal. 16 (2015), no. 9, 1925-1936.

[21] Berinde, V., Păcurar, M., A constructive approach to coupled fixed point theorems in metric spaces, Carpathian J. Math. 31 (2015), no. 3, 277-287.

[22] Berinde, V., Petric, M. A., Fixed point theorems for cyclic non-self singlevalued almost contractions, Carpathian J. Math. 31 (2015), no. 3, 289296.

[23] Bojor F., Fixed point of $\varphi$-contraction in metric spaces endowed with a graph, Ann. Univ. Craiova, Math. Comput. Sci. Ser., 37 (2010), no. 4, $85-92$.

[24] Bojor, F., Fixed points of Bianchini mappings in metric spaces endowed with a graph, Carpathian J. Math. 28 (2012), no. 2, 207-214

[25] Bojor, F., Fixed points of Kannan mappings in metric spaces endowed with a graph, An. Stiint. Univ. "Ovidius" Constanta Ser. Mat. 20 (2012), no. $1,31-40$

[26] Bojor, F., Fixed point theorems for Reich type contractions on metric spaces with a graph, Nonlinear Anal. 75 (2012), no. 9, 3895-3901

[27] Bojor, F., Fixed point theorems in in metric spaces endowed with a graph (in Romanian), PhD Thesis, North University of Baia Mare, 2012

[28] Caristi, J., Fixed point theorems for mappings satisfying inwardness conditions, Trans. Amer. Math. Soc. 215 (1976), 241-251 
[29] Caristi, J., Fixed point theory and inwardness conditions. Applied nonlinear analysis (Proc. Third Internat. Conf., Univ. Texas, Arlington, Tex., 1978), pp. 479-483, Academic Press, New York-London, 1979.

[30] Chatterjea, S.K., Fixed-point theorems, C.R. Acad. Bulgare Sci. 25 (1972) 727-730

[31] Chifu, C. Petruşel, Gabriela., Generalized contractions in metric spaces endowed with a graph, Fixed Point Theory Appl. 2012, 2012:161, 9 pp.

[32] Cho, S.-H., A fixed point theorem for a Cirić-Berinde type mapping in orbitally complete metric spaces. Carpathian J. Math. 30 (2014), no. 1, 63-70.

[33] Choudhury, B. S, Das, K., Bhandari, S. K., Cyclic contraction of Kannan type mappings in generalized Menger space using a control function. Azerb. J. Math. 2 (2012), no. 2, 43-55.

[34] Ćirić, Lj. B., A remark on Rhoades' fixed point theorem for non-self mappings, Internat. J. Math. Math. Sci. 16 (1993), no. 2, 397-400

[35] Ćirić, Lj. B., Quasi contraction non-self mappings on Banach spaces, Bull. Cl. Sci. Math. Nat. Sci. Math. No. 23 (1998), 25-31

[36] Ćirić, Lj. B., Ume, J. S., Khan, M. S. and Pathak, H. K., On some nonself mappings, Math. Nachr. 251 (2003), 28-33

[37] Eisenfeld, J. and Lakshmikantham, V., Fixed point theorems on closed sets through abstract cones. Appl. Math. Comput. 3 (1977), no. 2, 155167.

[38] Filip, A.-D., Fixed point theorems for multivalued contractions in Kasahara spaces. Carpathian J. Math. 31 (2015), no. 2, 189-196.

[39] Gabeleh, M., Existence and uniqueness results for best proximity points. Miskolc Math. Notes 16 (2015), no. 1, 123-131.

[40] Hussain, N.; Salimi, P.; Vetro, P., Fixed points for $\alpha-\psi$-Suzuki contractions with applications to integral equations. Carpathian J. Math. 30 (2014), no. 2, 197-207.

[41] Jachymski, J., The contraction principle for mappings on a metric space with a graph, Proc. Amer. Math. Soc. 136 (2008), no. 4, 1359-1373

[42] Kannan, R., Some results on fixed points, Bull. Calcutta Math. Soc. 10 (1968) $71-76$ 
[43] Kikkawa, M., Suzuki, T., Some similarity between contractions and Kannan mappings. II. Bull. Kyushu Inst. Technol. Pure Appl. Math. No. 55 (2008), 1-13.

[44] Kikkawa, M., Suzuki, T., Some similarity between contractions and Kannan mappings. Fixed Point Theory Appl. 2008, Art. ID 649749, 8 pp.

[45] Kirk W.A., Srinivasan P.S. and Veeramani P., Fixed points for mappings satisfying cyclical contractive conditions, Fixed Point Theory, 4 (2003), no. $1,79-89$

[46] Meszaros, J., A comparison of various definitions of contractive type mappings, Bull. Calcutta Math. Soc. 84 (2) (1992) 167-194

[47] Nicolae, Adriana, O'Regan, D. and Petruşel, A., Fixed point theorems for singlevalued and multivalued generalized contractions in metric spaces endowed with a graph, Georgian Math. J. 18 (2011), no. 2, 307-327

[48] Nieto, J. J., Rodriguez-Lopez, R., Contractive mapping theorems in partially ordered sets and applications to ordinary differential equations, Order 22 (2005), no. 3, 223-239 (2006)

[49] Nieto, J. J., Rodriguez-Lopez, R., Existence and uniqueness of fixed point in partially ordered sets and applications to ordinary differential equations, Acta. Math. Sin., (Engl. Ser.) 23(2007), no. 12, 2205-2212

[50] Panja, C., Samanta, S. K., On determination of a common fixed point. Indian J. Pure Appl. Math. 11 (1980), no. 1, 120-127.

[51] Nieto, Juan J.; Pouso, Rodrigo L.; Rodriguez-Lopez, Rosana, Fixed point theorems in ordered abstract spaces, Proc. Amer. Math. Soc. 135 (2007), no. $8,2505-2517$

[52] Păcurar, M., Approximating common fixed points of Prešić-Kannan type operators by a multi-step iterative method, An. Ştiinţ,. Univ. "Ovidius" Constanţa Ser. Mat. 17 (2009), no. 1, 153-168

[53] Păcurar, M., Iterative Methods for Fixed Point Approximation, Risoprint, Cluj-Napoca, 2010

[54] Păcurar, M., A multi-step iterative method for approximating fixed points of Prešić-Kannan operators, Acta Math. Univ. Comen. New Ser., 79 (2010), No. 1, 77-88 
[55] Păcurar, M., A multi-step iterative method for approximating common fixed points of Prešić-Rus type operators on metric spaces, Stud. Univ. Babeş-Bolyai Math. 55 (2010), no. 1, 149-162.

[56] Păcurar, M., Fixed points of almost Prešić operators by a k-step iterative method, An. Ştiint,. Univ. Al. I. Cuza Iaşi, Ser. Noua, Mat. 57 (2011), Supliment 199-210

[57] Petric, M., Some results concerning cyclical contractive mappings, Gen. Math. 18 (2010), no. 4, 213-226

[58] Petric, M., Best proximity point theorems for weak cyclic Kannan contractions, Filomat 25 (2011), no. 1, 145-154

[59] Petrusel, Adrian; Rus, Ioan A., Fixed point theorems in ordered L-spaces, Proc. Amer. Math. Soc. 134 (2006), no. 2, 411-418

[60] Ran, A. C. M., Reurings, M. C. B., A fixed point theorem in partially ordered sets and some applications to matrix equations, Proc. Amer. Math. Soc. 132 (2004), no. 5, 1435-1443

[61] Rhoades, B. E., A comparison of various definitions of contractive mappings, Trans. Amer. Math. Soc. 226 (1977) 257-290

[62] Rhoades, B. E., A fixed point theorem for some non-self-mappings, Math. Japon. 23 (1978/79), no. 4, 457-459

[63] Rhoades, B. E., Contractive definitions revisited, Contemporary Mathematics 21 (1983) 189-205

[64] Rhoades, B. E., Contractive definitions and continuity, Contemporary Mathematics 72 (1988) 233-245

[65] Rus, I. A., Principles and Applications of the Fixed Point Theory (in Romanian), Editura Dacia, Cluj-Napoca, 1979

[66] Rus, I. A., Generalized contractions, Seminar on Fixed Point Theory 3(1983) $1-130$

[67] Rus, I. A., Generalized Contractions and Applications, Cluj University Press, Cluj-Napoca, 2001

[68] Rus, I. A., Picard operators and applications, Sci. Math. Jpn. 58 (2003), No. $1,191-219$

[69] Rus, I. A., Private communication (2015) 
[70] Rus, I. A., Petruşel, A. and Petruşel, G., Fixed Point Theory, Cluj University Press, Cluj-Napoca, 2008

[71] Samanta, S. K., Fixed point theorems for non-self-mappings. Indian J. Pure Appl. Math. 15 (1984), no. 3, 221-232.

[72] Samanta, S. K., Fixed point theorems for Kannan maps in a metric space with some convexity structure. Bull. Calcutta Math. Soc. 80 (1988), no. $1,58-64$

[73] Samanta, C., Samanta, S. K., Fixed point theorems for multivalued nonself mappings. Zb. Rad. Prirod.-Mat. Fak. Ser. Mat. 22 (1992), no. 1, $11-22$

[74] Shukla, S., Abbas, M., Fixed point results of cyclic contractions in product spaces. Carpathian J. Math. 31 (2015), no. 1, 119-126.

[75] Sun, Y. I., Su, Y. F., Zhang, J. L., A new method for the research of best proximity point theorems of nonlinear mappings. Fixed Point Theory Appl. 2014, 2014:116, 18 pp.

[76] Ume, J. S., Fixed point theorems for Kannan-type maps. Fixed Point Theory Appl. 2015, 2015:38, 13 pp.

[77] Zhang, J. L., Su, Y. F., Best proximity point theorems for weakly contractive mapping and weakly Kannan mapping in partial metric spaces. Fixed Point Theory Appl. 2014, 2014:50, 8 pp.

Laszlo BALOG,

Department of Mathematics and Computer Science,

North University Center at Baia Mare,

Victorie1 76, 430122 Baia Mare Romania.

Email: balog58@yahoo.com

Vasile BERINDE,

Department of Mathematics and Computer Science,

North University Center at Baia Mare,

Victorie1 76, 430122 Baia Mare Romania.

Email: vberinde@ubm.ro

Department of Mathematics and Statistics,

King Fahd University of Petroleum and Minerals,

Dhahran, Saudi Arabia.

E-mail: vasile.berinde@gmail.com

Mădălina PĂCURAR,

Department of Statistics, Analysis, Forecast and Mathematics,

Faculty of Economics and Bussiness Administration,

Babeş-Bolyai University of Cluj-Napoca,

Cluj-Napoca Romania.

Email: madalina.pacurar@econ.ubbcluj.ro 